\title{
Nano-silica as reinforcing filler in NR latex: Role of processing method on filler morphology inside the rubber and properties of the nanocomposite
}

\author{
G. Neena ${ }^{1 *}$, S. R. Amrutha ${ }^{1}$, J. Rani ${ }^{2}$, P. M. Jose ${ }^{3}$, A. Mathiazhagan $^{4}$ \\ ${ }^{1}$ Post graduate and Research Department of Chemistry, Maharaja's College, Ernakulam, 682011 Kerala, India \\ ${ }^{2}$ Department of Polymer Science and Rubber Technology, Cochin University of Science and Technology, Kochi, 682022 \\ Kerala, India \\ ${ }^{3}$ Primus Gloves Pvt Ltd, Plot no: 14-,A, cochin special economic zone, Kakkanad, Cochin, 682037 Kerala, India \\ ${ }^{4}$ Department of Ship Technology, Cochin University of Science and Technology, Kochi, 682022 Kerala, India
}

Received 5 May 2021; accepted in revised form 9 July 2021

\begin{abstract}
The processing method of a polymer composite plays an important role in determining the filler morphology inside the polymer matrix, which in turn influences the overall properties of the composite. In the present work, colloidal nano-silica was mixed with natural rubber (NR) latex, and the nanocomposites were made by two distinct processes. The first method was simple film casting, which helped to generate a segregated filler network by arranging nano-silica along the outskirts of the rubber latex circles on drying. The second method involved latex co-coagulation with nano-silica, followed by melt mixing in an internal mixer which shattered the segregated network and yielded a random distribution of nano-silica in the NR matrix. The study revealed that irrespective of the processing method and filler morphology, incorporation of nano-silica in NR significantly improved the mechanical and solvent resistance properties in both cases without affecting thermal stability.
\end{abstract}

Keywords: rubber, nanocomposites, nano-silica, segregated network, mechanical properties

\section{Introduction}

Fast depleting fossil fuels and crucial environmental problems that we face in daily life urge the demand for natural renewable resources. Many works are underway in the field of rubber technology with the aim of replacing carbon black with environment-friendly silica. Because the silica/silane technology used in high-performance tires (Green tires) reduces rolling resistance and hence results in better fuel economy. A high-performance tyre can improve the fuel efficiency of the vehicle by around $8-10 \%$ by minimizing the rolling resistance [1]. Traditional mixing processes, on the other hand, cause an increase in viscosity due to the weak filler-rubber interactions and high filler-filler interactions displayed by silica, making processing extremely difficult. To compensate for the incompatibility of inorganic silica with organic rubber, expensive coupling agents are frequently used. If the silica addition procedure is made simpler and enough coupling agents can be provided at a reasonable rate, silica technology will become a promising one in the coming years.

Silica plays an important role in the rubber industry as reinforcing mineral filler owing to its ability to impart high tensile strength, tear strength, abrasion resistance, low heat build-up, rolling resistance, etc., to the rubber composite [2]. Conventional mixing of silica with rubber usually results in non-uniform silica 
distribution in the matrix of rubber. Moreover, the polar silanol groups residing on the surface of silica facilitate intense silica-silica interaction and provokes aggregation of silica particles, causes poor dispersion in a non-polar rubber matrix such as Natural Rubber (NR) leading to poor mechanical properties [3, 4].

To overcome the difficulties with the incorporation of silica in rubber, many researchers have tried the in-situ precipitation of silica in NR latex, and such composites are reported to have superior mechanical properties [5-7]. Prasertsri and Rattanasom [8] obtained improved mechanical and dynamic properties for the NR composites reinforced with fumed and precipitated silica. They have prepared natural rubber masterbatches by adding the aqueous suspensions of fumed and precipitated silica into the NR latex and obtained good distribution of silica particles in the rubber matrix. Prasertsri and Rattanasom [9] have also reported the preparation of NR-composites from NR/silica masterbatches in which silica suspensions were prepared using a laboratory agitator bead mill that resulted in good silica dispersion in NR latex. The composite prepared were compared with those prepared by a conventional method, with and without adding silane-coupling agent (Si-69), and their results revealed that the NR/silica masterbatches having more than $10 \mathrm{phr}$ of silica exhibited superior mechanical properties.

The morphology of filler inside the rubber is largely influenced by the processing method. In rubber nanocomposites, better dispersion of the nanofillers in the rubber is a major component in achieving significant improvements in properties. In the present study, latex stage incorporation of colloidal nano-silica to the NR has been done. The work consists of two parts. First part deals with the film casting and curing of nanosilica/natural rubber latex compounds. The second part deals with the co-coagulation of the colloidal nano-silica with NR latex, followed by blending in an internal mixer. The dependence of the processing method on nanocomposite morphology is investigated, and differences in the mechanical, thermal, and solvent barrier properties of the two types of nanocomposites with respect to filler distribution are also analyzed.

\section{Experimental}

\subsection{Materials}

The total solid content (TSC) of the colloidal nanosilica used for the study was $33 \%$ and had a $\mathrm{pH}$ of approximately 10. It was supplied by Bee Chems, Kanpur. The size of the nano-silica particles was $10 \pm 5 \mathrm{~nm}$. Centrifuged NR latex of $60 \%$ DRC was supplied by Njavalli latex, Kochi, India. Commercial grade chemicals have been used for compounding the rubber.

\subsection{Preparation of $\mathrm{NR} /$ nano-silica composites}

Two alternative procedures were used to make NR/ nano-silica composites. In one method, the nanocomposites were made by mixing nano-silica with NR latex, then compounding, film casting, and curing; thus, they are labeled as NRSF, with the silica content expressed in parts per hundred [phr] as the suffix. The second approach involved coagulating nano-silicacontaining NR latex, drying it, then melt blending it with compounding ingredients using an internal mixer: Haake, followed by compression molding. These composites were labeled as NRSH with a suffix of silica in phr. The detailed procedure is given below.

\subsubsection{NRSF nanocomposites by film casting}

Nano-silica colloid was diluted with distilled water and sonicated for 15 minutes using an ultrasonic processor with a probe tip diameter of $13 \mathrm{~mm}$ (Vibracell Processor VC 750) to separate aggregated nano-silica particles using high energy. These dispersions were added to the NR latex $(60 \% \mathrm{DRC})$ to get the nano-silica concentration of 1, 2, 3, 4, and $5 \mathrm{phr}$ in the dry NR. These mixtures were sonicated further for 15 minutes in a bath-type sonicator having $70 \mathrm{~W}$ power and $42 \mathrm{kHz}$ frequency to ensure the homogeneous dispersion of silica particles within the latex. Compounding of the latex mix was done as per the formulation in Table 1. The latex compound has been kept for 24 hours and poured onto glass trays. The films were dried at $50^{\circ} \mathrm{C}$ for $24 \mathrm{~h}$ and curing was done in an air oven at $100^{\circ} \mathrm{C}$ for $20 \mathrm{~min}$.

Table 1. Formulation of NRSF composites.

\begin{tabular}{|l|c|}
\hline \multicolumn{1}{|c|}{ Ingredients } & $\begin{array}{c}\text { Amount } \\
\text { [g] }\end{array}$ \\
\hline NR latex (60\% DRC) & 167 \\
\hline Nano-silica & $0,1,2,3,4,5$ \\
\hline KOH solution (10\%) & 1 \\
\hline Potassium oleate solution (10\%) & 1 \\
\hline Vulcastab VL (20\%) & 1 \\
\hline ZnO dispersion (50\%) & 2 \\
\hline ZDC dispersion $(50 \%)$ & 3 \\
\hline Sulphur dispersion $(50 \%)$ & 1 \\
\hline
\end{tabular}




\subsubsection{NRSH nanocomposites by Haake mixing}

Nano-silica dispersions after sonication (as mentioned before) were added to the NR latex at various compositions to get the nano-silica concentration of $1,3,5$, and $7 \mathrm{phr}$ in the dry NR. These mixtures were stirred well using a magnetic stirrer for 15 minutes to achieve uniform distribution of filler in the NR matrix. After that, the latex mixes were poured into trays and coagulated by rapid addition of $2 \% \mathrm{v} / \mathrm{v}$ acetic acid solution. The coagula were isolated by vacuum filtration; excess acid was removed by repeated washings with water and kept at $50^{\circ} \mathrm{C}$ in an air oven for drying. The dried coagulum containing nano-silica was mixed in an internal mixer (Thermo Haake, at $70^{\circ} \mathrm{C}, 8 \mathrm{~min}, 60 \mathrm{rpm}$ ) with compounding ingredients as per formulation given in Table 2 and procedure outlined in the ASTM D 3182. The mixed batch was passed six times through tight nip in a two-roll mill and was finally sheeted out. The samples were kept overnight for maturation. The rubber compounds were compression molded to get NRSH nanocomposites.

\subsection{Characterization}

Nano-silica was characterized using FTIR, BET, SEM, HRTEM, EDX, XRD and Particle size analyzer. Fourier transform infrared spectroscopy (FTIR) characterization of nano-silica was done using Thermo Nicolet, Avatar 370 model IR spectrometer, in the $4000-500 \mathrm{~cm}^{-1}$ spectral range. BET surface area, pore-volume, and pore diameter of nano-silica were measured at $77 \mathrm{~K}$ by Micromeritics (TriStar 3000 V6.07 A) using nitrogen adsorption.

Dynamic light scattering (DLS)system; (Nanotrac equipment from Microtrac) was used for the measurement of the size of colloidal silica particles. The principle of the DLS is based on the illumination of the sample by a Laser beam followed by the detection of

Table 2. Formulation of NRSH composites.

\begin{tabular}{|l|c|}
\hline \multicolumn{1}{|c|}{ Ingredients } & $\begin{array}{c}\text { Amount } \\
\text { [phr] }\end{array}$ \\
\hline $\mathrm{NR}$ & 100 \\
\hline Nano-silica & $0,1,3,5,7$ \\
\hline Stearic acid & 2.25 \\
\hline ZnO & 5.0 \\
\hline Antioxidant SP & 1.0 \\
\hline Accelerator MOR & 0.75 \\
\hline Accelerator TMTD & 0.2 \\
\hline Sulphur & 2.5 \\
\hline
\end{tabular}

the resultant fluctuation of the scattered light at a known scattering angle $(\theta)$ by a fast photon detector. Scanning electron micrographs of nano-silica and fracture surface of nanocomposites were examined using a JEOL Model JSM.6390 LV scanning electron microscope. HRTEM images of nano-silica, NRSF, and NRSH nanocomposites were examined using a high-resolution transmission electron microscopy (HRTEM, JEOL model JEM-2100).

$\mathrm{X}$-ray diffraction study of nano-silica was done using a Bruker AXS D8 Advance X-ray powder diffractometer equipped with $\mathrm{Cu} \mathrm{K} \alpha$ radiation at the operating voltage of $40 \mathrm{kV}$ and current of $35 \mathrm{~mA}$. The diffraction intensities were recorded between 3 and $80^{\circ}$ ( $2 \theta$ angle range) at increments of $0.02^{\circ}$ at a wavelength of $1.541 \AA$.

Dumb-bell-shaped specimens were used for the tensile test and angle-shaped specimens for the tear test in Universal Testing Machine of $10 \mathrm{kN}$ load capacity (Shimadzu Autograph AG-I series). The test was done according to ASTM D 412 for tensile strength and ASTM D 624 for tear strength. Dynamic mechanical analyzer (Model Q 800, TA instruments) was used for the strain sweep studies of the vulcanizates at room temperature. The test was done in tension mode using the strain amplitude range of 0.01 to $40 \%$ at $1 \mathrm{~Hz}$ frequency.

Solvent swelling studies were done by soaking the samples in toluene. Circular samples punched from the cured sheets were used for the study. Samples were weighed and dipped in $30 \mathrm{ml}$ of toluene in glass bottles. Samples were taken out at regular time intervals, removed the excess solvent with tissue paper, weighed, and replaced into the bottles. The process continued till the weight remained constant, i.e., until they have reached equilibrium swelling. The samples were dried and weighed to get the deswollen weight. Thermal degradation studies were done on TGA-Q 50 Thermal Analyser (TA Instruments) under nitrogen atmosphere. Samples weighing 5-10 mg were subjected to the thermogravimetric analysis (TGA) within the temperature range of $40-700^{\circ} \mathrm{C}$, at a heating rate of $20^{\circ} \mathrm{C} / \mathrm{min}$.

\section{Results and discussion}

\subsection{Characterisation of nano-silica}

\subsubsection{Fourier transform infrared spectroscopy} (FTIR)

Figure 1 illustrates the FTIR spectral peaks obtained for nano-silica, thereby confirming its structure. A 


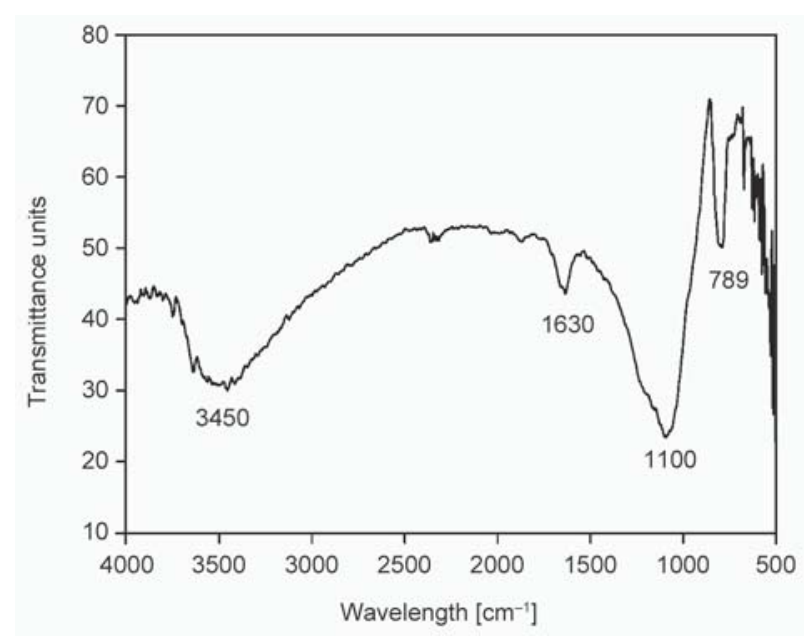

Figure 1. FTIR spectrum of nano-silica.

broad peak around $3455 \mathrm{~cm}^{-1}$ is credited to the presence of adsorbed water and hydrogen-bonded silanol groups. Peak at $790 \mathrm{~cm}^{-1}$ is due to $\mathrm{Si}-\mathrm{O}-\mathrm{Si}$ symmetric stretching and the one at $1100 \mathrm{~cm}^{-1}$ corresponds to the $\mathrm{Si}-\mathrm{O}$ symmetric stretching. The bending vibration mode of water gives the peak at $1630 \mathrm{~cm}^{-1}[10,11]$.

\subsubsection{BET surface area analysis}

The BET surface area, pore-volume, and pore size of the silica obtained after charring of the NR/nanosilica masterbatch in a muffle furnace at $550^{\circ} \mathrm{C}$ are given in Table 3. The results indicate that the nanosized silica particles have a large surface area which is beneficial in reinforcement, and the large pore volume provides enough space for the rubber chains to enter into the pores [12].

Table 3. BET analysis of nano-silica.

\begin{tabular}{|c|c|c|}
\hline $\begin{array}{c}\text { BET surface area } \\
{\left[\mathbf{m}^{2} / \mathbf{g}\right]}\end{array}$ & $\begin{array}{c}\text { Pore volume } \\
{\left[\mathbf{c m}^{\mathbf{3}} / \mathbf{g}\right]}\end{array}$ & $\begin{array}{c}\text { Pore size } \\
{[\AA]}\end{array}$ \\
\hline 235.7 & 1.14 & 180.3 \\
\hline
\end{tabular}

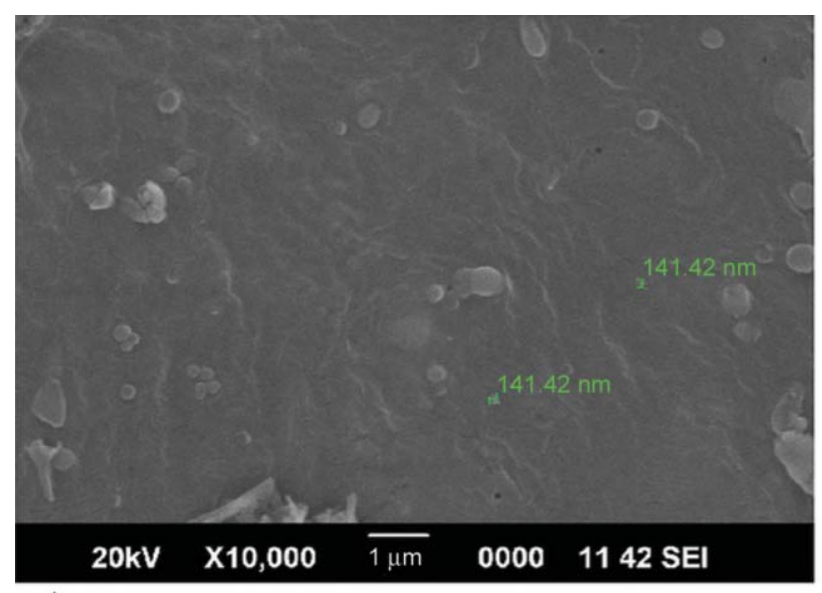

a)

Figure 3. Microscopic images of nano-silica using (a) SEM and (b) TEM.

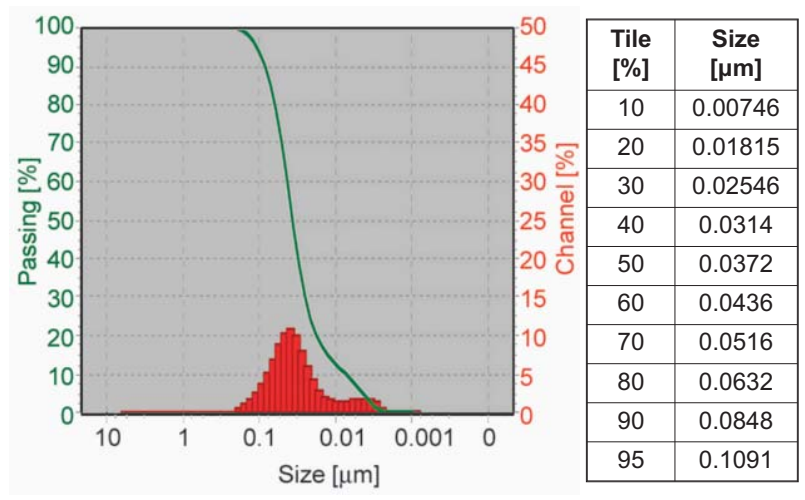

Figure 2. Particle size distribution of nano-silica.

\subsubsection{Particle size analysis by DLS}

Colloidal silica consists of dense, amorphous particles of $\mathrm{SiO}_{2}$. Most colloidal silicas are monodisperse suspensions with particle sizes ranging from 2 to $100 \mathrm{~nm}$ in diameter. The particle size distribution of nano-silica in the colloidal nano-silica suspension after sonication is clear from Figure 2, which shows a broad peak with $90 \%$ of the particles having a size less than $0.85 \mu \mathrm{m}$.

\subsubsection{Morphological studies of nano-silica}

SEM and TEM images of nano-silica give a clear picture of the particles at the microscopic level. SEM analysis supports (Figure 3a) the highly aggregated nature of nano-silica with particles around $140 \mathrm{~nm}$ diameter. Individual particles are not clear from the SEM image, whereas TEM (Figure 3b) clearly shows spherical nano-silica particles in the colloid having less than $10 \mathrm{~nm}$ diameter.

\subsubsection{Energy-dispersive X-ray spectroscopy (EDS)}

EDS spectrum of nano-silica is given in Figure 4. Only $\mathrm{Si}$ and $\mathrm{O}$ atoms exhibit sharp peaks in the figure

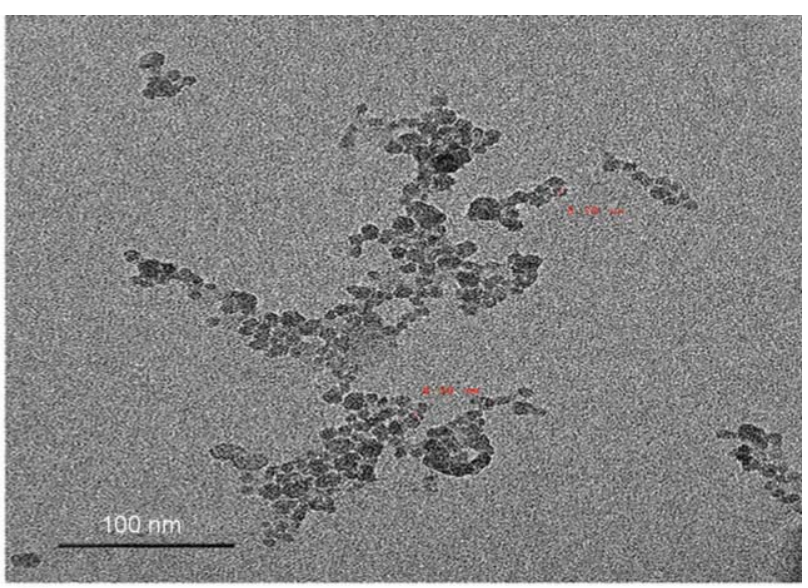

b) 


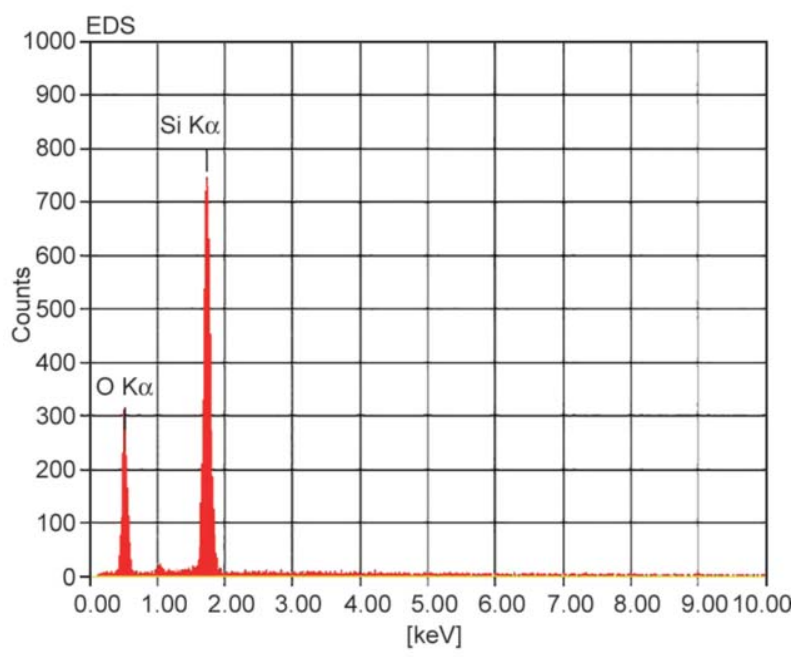

Figure 4. EDS spectrum of nano-silica.

and thereby confirm the high chemical purity of the sample.

\subsubsection{X-ray diffraction analysis (XRD)}

Figure 5 represents the powder $\mathrm{X}$-ray diffraction pattern displayed by nano-silica. The spectrum shows a broad band with a Bragg angle of $2 \theta=19.2^{\circ}$, indicating the amorphous nature of silica [13].

\subsection{Microstructure and fracture surface morphology}

TEM micrographs (Figure 6) clearly differentiate the microstructure of the NRSH and NRSF nanocomposite. The images provide clear supporting evidence for the suggestion that the processing method has a major role in determining the filler morphology in the polymer matrix. Nano-silica particles are uniformly distributed in the NRSH nanocomposite, whereas in

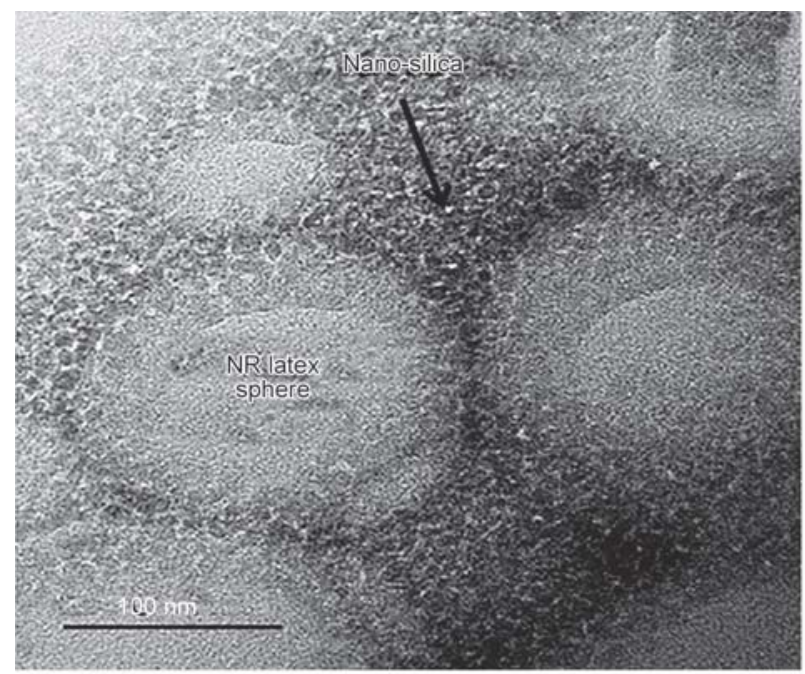

a)

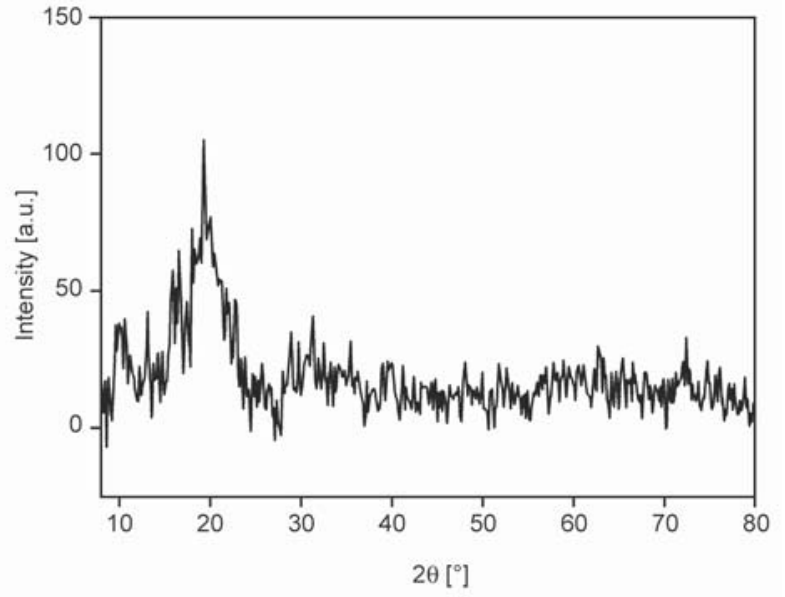

Figure 5. XRD patterns of nano-silica.

the NRSF composite, they form a segregated structure. During film formation in NRSF composites, evenly scattered nano-silica particles in the latex are pushed to the interstitial sites between the rubber particles, giving a web-like nano-silica network inside the rubber. Similar rubber nanocomposites with a segregated network of fillers have been reported in our previous studies [14-16].

The processing method adopted for the NRSH composite is different, which involves co-coagulation of the NR latex and colloidal nano-silica followed by mixing the dry coagulum in Haake mixer as mentioned before. The web-like nano-silica network formed in the coagulum is broken by the intense shear forces in the internal mixer, and the final sample has uniformly distributed nano-silica particles in the NR matrix.

The schematic representation proposed for the preparation of NRSF and NRSH nanocomposites is shown

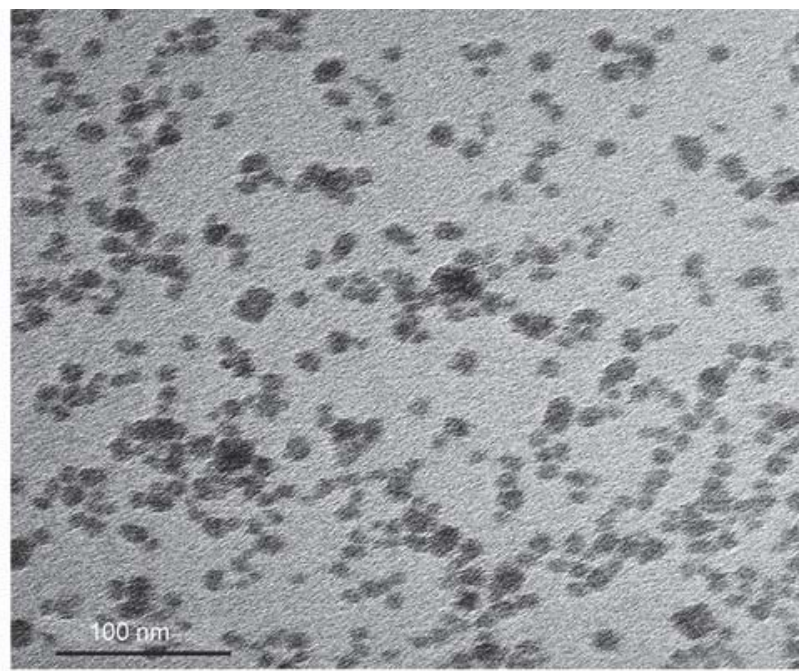

b)

Figure 6. TEM images of (a) NRSF4 and (b) NRSH5 composite film formed on the TEM grid. 


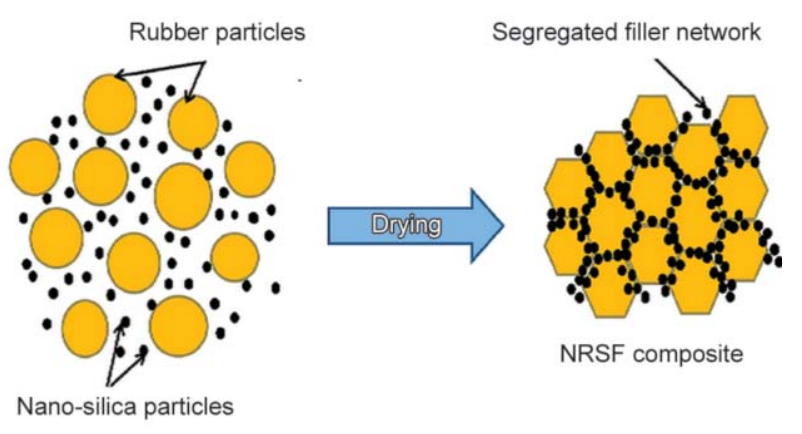

Figure 7. Schematic representation of the preparation of NRSF nanocomposites with segregated nano-silica network.

in Figures 7 and 8, respectively. In NRSF, colloidal nano-silica blends uniformly in the NR latex compound and are pushed to the fringe of rubber circles on drying and are held at the interfaces of the rubber particles. The segregated nano-silica structure remains the same even after curing since the highly viscous nature of crosslinked rubber prevents the nanofillers from getting inside the rubber. In the case of NRSH composites, nano-silica particles are aligned at the boundary of the rubber spheres on coagulation to give a segregated filler structure. When the dried coagulum is subjected to blending in an internal mixer, the network is destroyed, and a composite with well-dispersed nano-silica particles is obtained.

SEM images of the tensile and tear fracture surfaces of the NRSF and NRSH composites are shown in Figure 9 and 10, respectively. These images again support the difference in filler morphology between the two composites. The tensile (Figure $9 b$ and 9c) and tear (Figure 9e and 9f) fracture surfaces of NRSF composites show special patterns, whereas the surface seems to be relatively smooth in the NRSH composites (Figure 10). Patterns in NRSF suggest that the fracture occurs with difficulty, implying that the sample has a high resistance to failure because here nano-silica forms a 3D network throughout the matrix due to the arrangement of nano-silica at the periphery of the spherical rubber particles. The relatively smooth surface of NRSH shows that nano-silica is distributed evenly throughout the NR. The surface roughness of both composites results from the deviation in tensile and tear paths caused by the presence of nano-silica.

\subsection{Mechanical properties}

Stress-strain behavior of NRSF and NRSH nanocomposites is depicted in Figure 11a and 11b, respectively. Both composites exhibit sigmoidal-shaped stressstrain curves representing strain-induced crystallization at high strain. Strain-induced crystallization seems to be more prominent with the addition of filler, indicating the reinforcing nature of nano-silica [5]. The sharp increment in stress around $400 \%$ elongation is due to the orientation and disentanglement of natural rubber chains [17].

Table 4 summarises the mechanical properties of pure NR, NRSF, and NRSH nanocomposites. Nanosilica loading improves the mechanical properties of both NRSF and NRSH composites, regardless of the processing conditions. Both nanocomposites show a significant increase in tensile strength, tear strength, and tensile modulus (at 300\% elongation) due to the effective reinforcement of nano-silica. For NRSF4, the tensile strength improves by $60 \%$, and for NRSH5, the enhancement is $38 \%$. NRSF5 has a $90 \%$

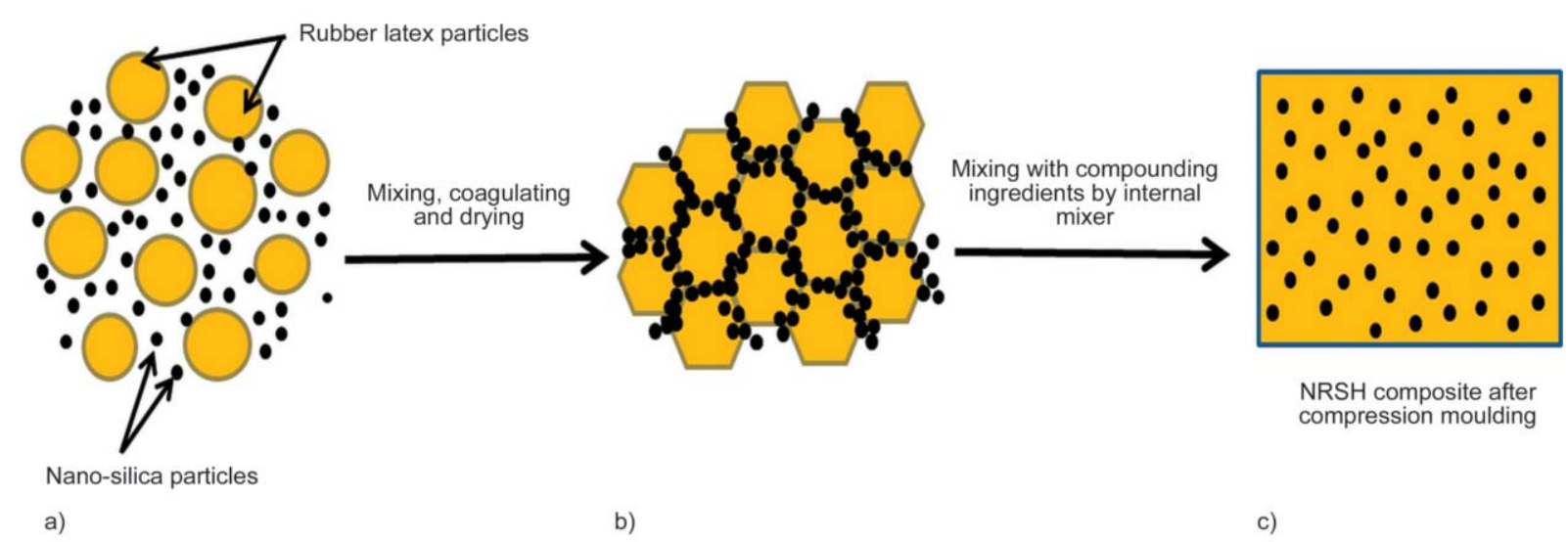

Figure 8. Schematic representation of the preparation of NRSH nanocomposites by latex coagulation followed by Haake mixing. (a) Colloidal nanosilica particles uniformly distributed in the NR latex; (b) nanosilica form segregated structure in the rubber matrix on coagulation and drying; (c) Mixing in an internal mixer with compounding ingredients breaks the segregated network and homogeneously distributes the silica particles in the NR matrix. 


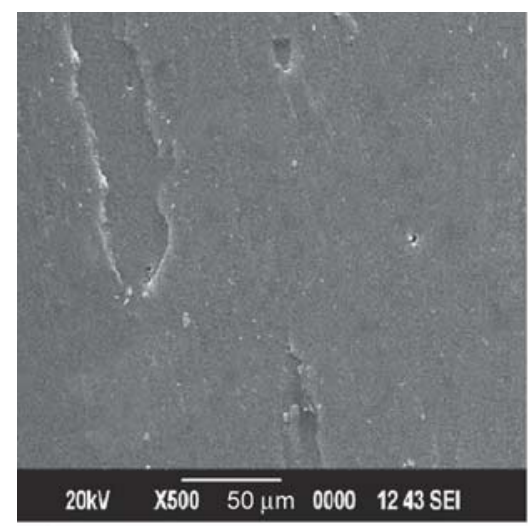

a)

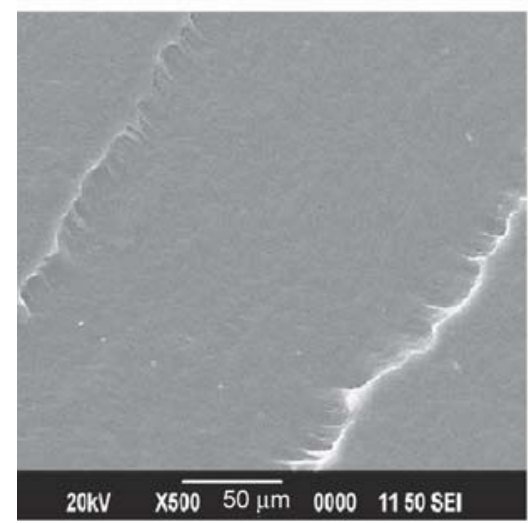

d)

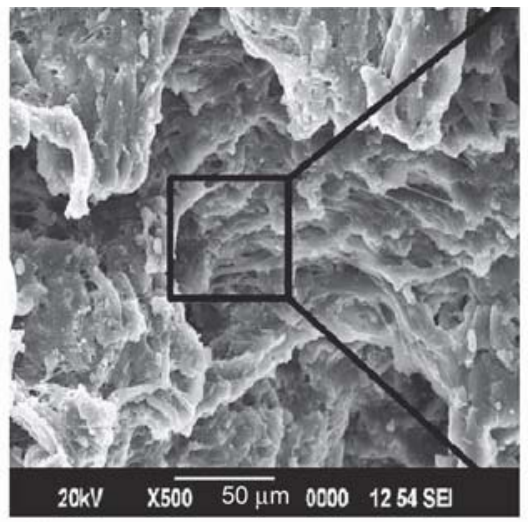

b)

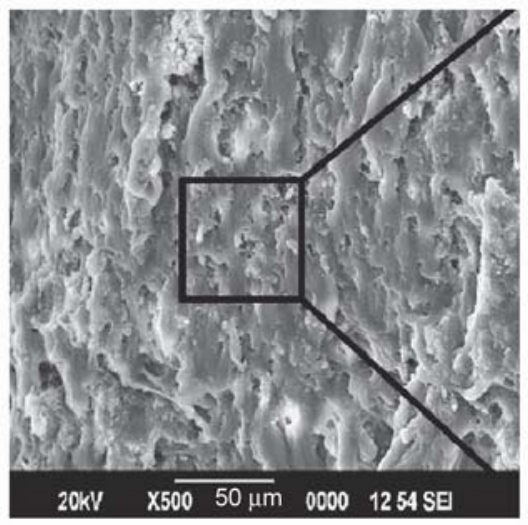

e)

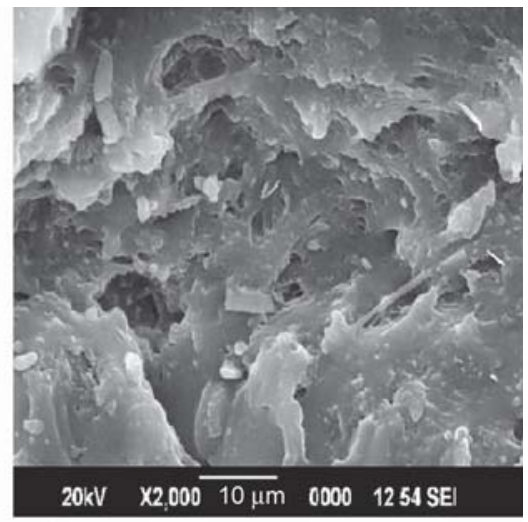

c)

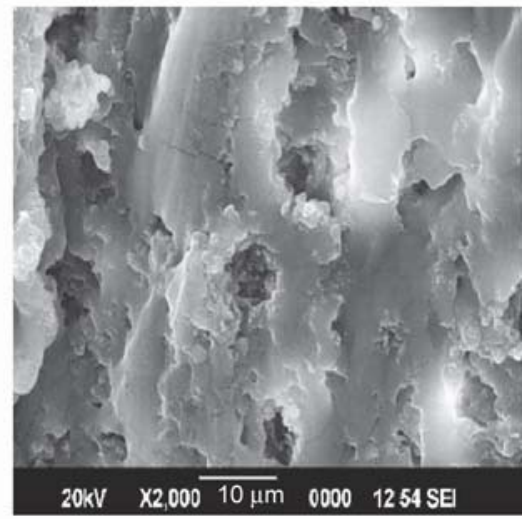

Figure 9. Scanning electron micrographs of the fracture surfaces of NRSF nanocomposites: tensile fracture surfaces of (a) NR, (b) and (c) NRSF4; tear fracture surfaces of (d) NR, (e) and (f) NRSF5.

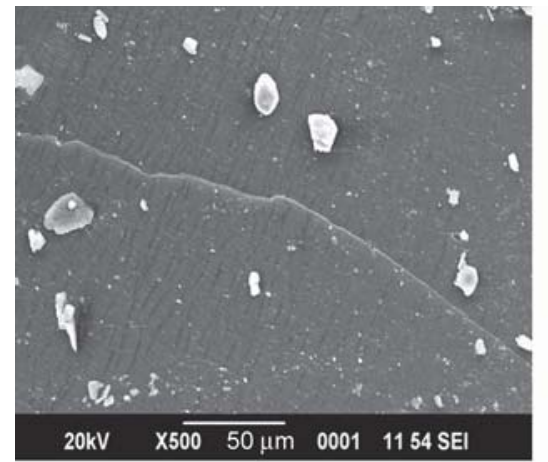

a)

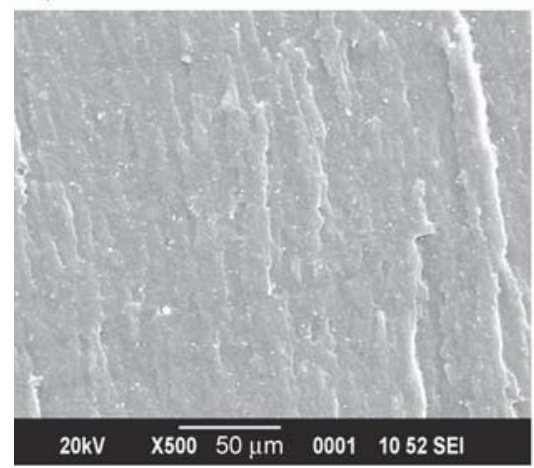

d)

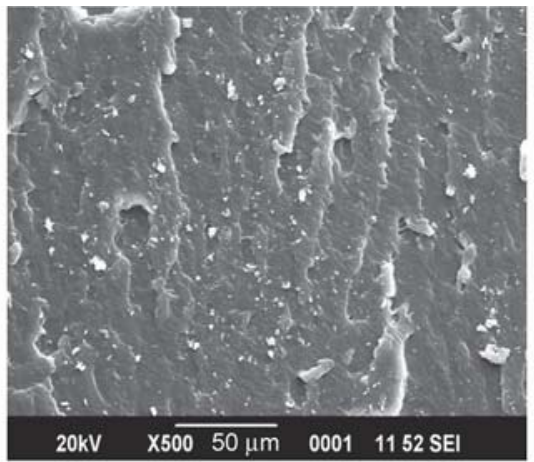

b)

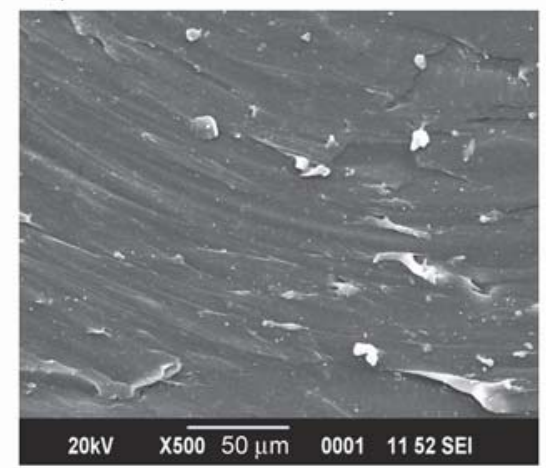

e)

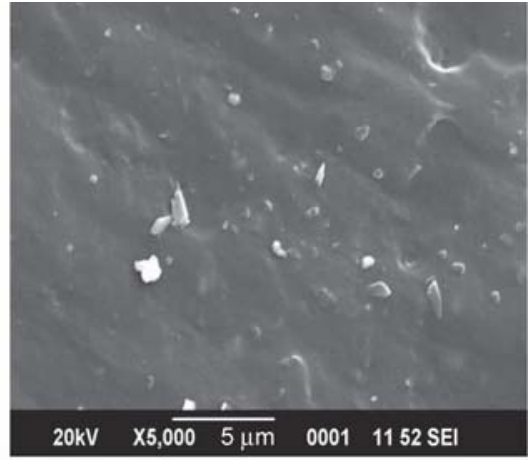

c)

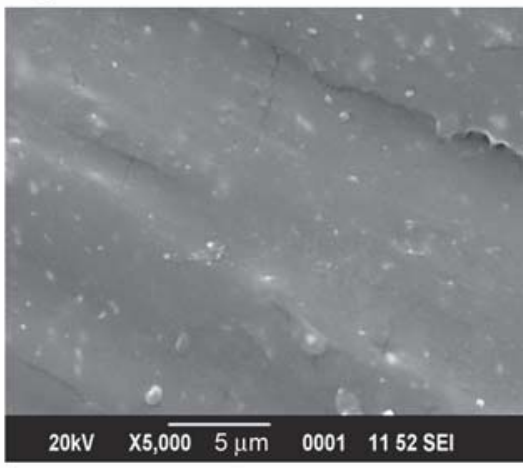

f)

Figure 10. Scanning electron micrographs of the fracture surfaces of NRSH nanocomposites: tensile fracture surfaces of (a) NR, (b) and (c) NRSH5; tear fracture surfaces of (d) NR, (e) and (f) NRSH5. 


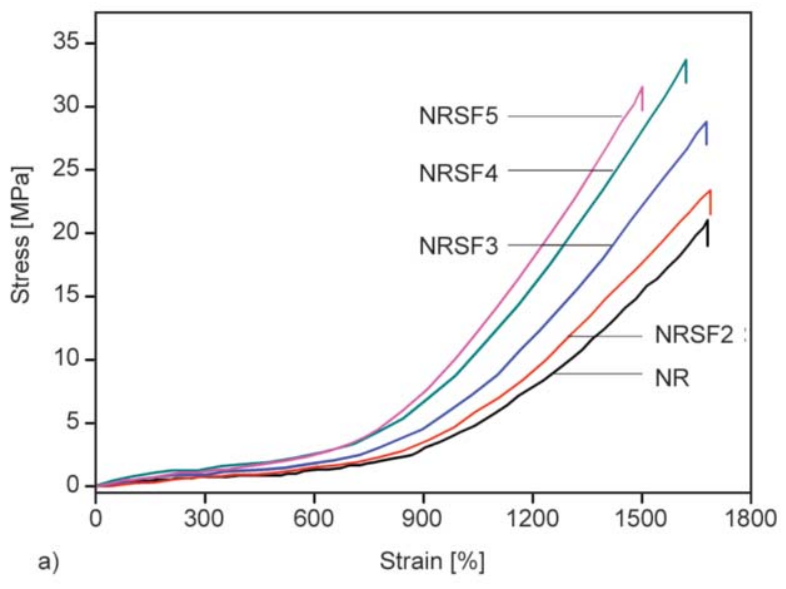

Figure 11. Stress-strain curves of NR, NRSF (a) and NRSH

Table 4. Mechanical properties of NRSF and NRSH nanocomposites.

\begin{tabular}{|l|c|c|c|c|}
\hline $\begin{array}{c}\text { Sample } \\
\text { name }\end{array}$ & $\begin{array}{c}\text { Tensile } \\
\text { strength } \\
{[\mathbf{M P a}]}\end{array}$ & $\begin{array}{c}\text { Elongation } \\
\text { at break } \\
{[\%]}\end{array}$ & $\begin{array}{c}\text { Modulus } \\
\mathbf{3 0 0 \%} \\
{[\mathbf{M P a}]}\end{array}$ & $\begin{array}{c}\text { Tear } \\
\text { strength } \\
{[\mathbf{N} / \mathbf{m m}]}\end{array}$ \\
\hline NRSF0 & $21.0 \pm 0.5$ & $1691 \pm 10$ & $1.06 \pm 0.08$ & $34.8 \pm 1.2$ \\
\hline NRSF1 & $23.0 \pm 0.6$ & $1638 \pm 48$ & $1.24 \pm 0.09$ & $59.0 \pm 5.4$ \\
\hline NRSF2 & $23.9 \pm 0.8$ & $1674 \pm 46$ & $1.46 \pm 0.03$ & $79.5 \pm 2.2$ \\
\hline NRSF3 & $28.8 \pm 0.5$ & $1677 \pm 18$ & $1.48 \pm 0.05$ & $82.4 \pm 1.9$ \\
\hline NRSF4 & $33.7 \pm 1.2$ & $1621 \pm 27$ & $1.95 \pm 0.10$ & $83.5 \pm 0.6$ \\
\hline NRSF5 & $31.7 \pm 0.6$ & $1501 \pm 37$ & $2.02 \pm 0.24$ & $89.5 \pm 3.4$ \\
\hline NRSH0 & $25.4 \pm 0.4$ & $1154 \pm 52$ & $1.96 \pm 0.09$ & $36.7 \pm 0.5$ \\
\hline NRSH1 & $28.7 \pm 1.1$ & $1131 \pm 42$ & $1.96 \pm 0.08$ & $38.5 \pm 0.9$ \\
\hline NRSH3 & $34.2 \pm 0.6$ & $1164 \pm 64$ & $2.27 \pm 0.10$ & $45.4 \pm 1.1$ \\
\hline NRSH5 & $35.1 \pm 0.9$ & $1118 \pm 55$ & $2.50 \pm 0.06$ & $47.3 \pm 0.4$ \\
\hline NRSH7 & $32.5 \pm 1.4$ & $1094 \pm 88$ & $2.28 \pm 0.04$ & $32.7 \pm 0.7$ \\
\hline
\end{tabular}

improvement in modulus at $300 \%$ elongation, while NRSH5 has a $28 \%$ improvement. Poor tear resistance is one of the issues with natural rubber latex products. Table 4 shows that the tear strength of NRSF5 and NRSH has increased by 157 and 29\%, respectively, as compared to pristine NR. Dramatic improvement of tear strength in NRSF composite is due to the presence of a segregated network of nano-silica in them. This network deflects or arrests the growing cracks, thereby giving further resistance to failure [18]. Better filler distribution inside the rubber improves rubber-filler interactions and imparts better mechanical properties through dissipation of external energy by viscoelastic processes [19].

Elongation at break for both NRSF and NRSH samples remains the same for all the compositions, with a slight decrease observed for the NRSF5. This is because the effect of nano-silica on the elongation at break of NR appears to be negligible at low loading

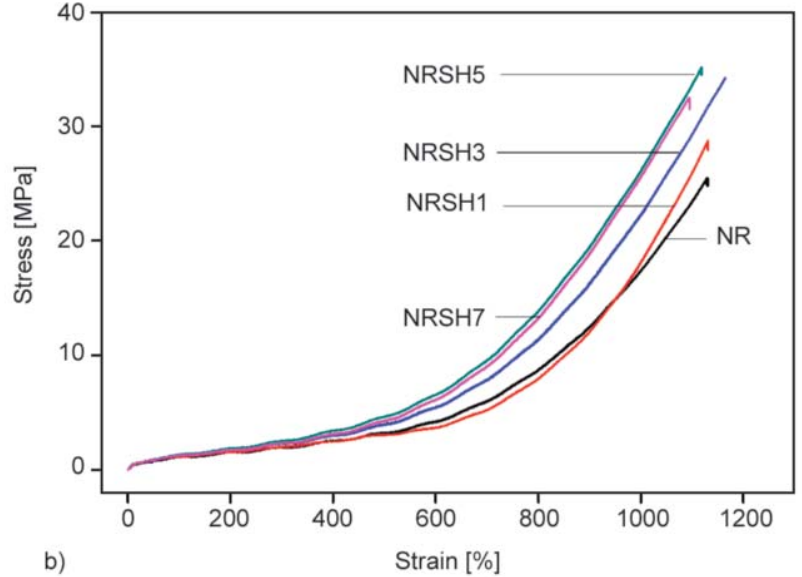

(b) nanocomposites.

but becomes significant at high loading. The slight decrease in elongation at break observed in NRSF for 5 phr nano-silica loading suggests that as the filler concentration increases, more fillers are accommodated in the interstitial regions between the rubber particles preventing inter-particle diffusion of rubber chains and causing failure at lower strain than neat rubber [20]. There have been reports of segregated structured composites with a significant rise in modulus and a sharp decrease in elongation at break [21, 22]. Here modulus has been improved for NRSF nanocomposites without drastically affecting the elongation at break. This is owing to better silicarubber interactions, as well as good silica dispersion in the rubber matrix [4].

When compared to film cast samples, tensile strength and modulus of Haake mixed samples are superior. This can be explained in terms of higher crosslink density exhibited by the Haake mixed sample than the film cast sample. The rigid network of nano-silica located in the interstitial spaces between the rubber spheres is responsible for a significant improvement in the mechanical properties of the NRSF nanocomposites. This network aids in the dissipation of a considerable quantity of energy through the interface and increases the sample's load-bearing capacity [23]. In both cases, the increasing trend in mechanical characteristics is halted after a certain concentration, which could be related to the agglomeration of nanosilica particles at higher concentrations [24]. In the case of NRSF nanocomposites, in addition to agglomeration, the film casting method used, along with poor filler dispersion at higher concentrations, results in micro-void formation in the segregated filler channel resulting in poor mechanical properties $[25,26]$. 

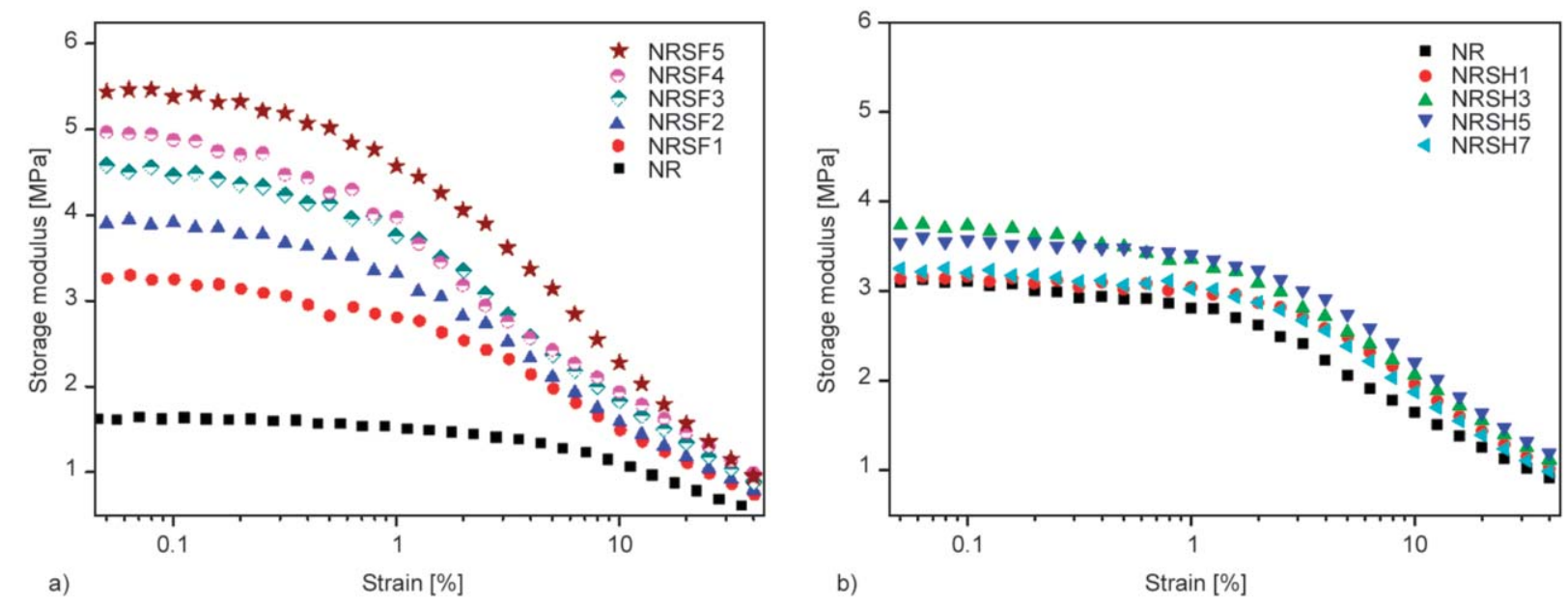

Figure 12. Variation of storage modulus with strain of (a) NRSF and (b) NRSH nanocomposites.

\subsection{Payne-effect}

Figure 12a depicts the variation in storage modulus $\left(E^{\prime}\right)$ with strain for NRSF nanocomposites, while Figure $12 \mathrm{~b}$ shows the behaviour of NRSH nanocomposites. The strain dependency behavior of $E^{\prime}$ differs dramatically in both cases. Due to the ability of hydrogen bond formation, silica enables strong filler networking [27]. A decrease in $E^{\prime}$ with strain at small amplitude is attributed to the breakdown of this filler network and is called the Payne effect [28]. This effect is more noticeable in NRSF composites, but it is less apparent in NRSH composites. This is strong evidence for the difference in nano-silica distribution in the two samples. In NRSF, with a segregated structure, the silica-silica network is more prominent, resulting in a significant drop in $E^{\prime}$ with strain. The quantity of filler-filler interaction in NRSH composites with a random distribution of silica is less, and hence the magnitude of the Payne effect is reduced. In both samples, neat rubber also shows a strain-dependent variation in storage modulus, which can be explained in terms of the entanglement network present, as suggested by Meera et al. [29].

The Payne effect is crucial to realize the reinforcement process of filled rubber samples [30]. The fillerfiller network is indicated by modulus at low strain $(5 \%)$, specifically the $\left(E_{0}-E_{\infty}\right)$. Networking improves as a result of filler loading. As the load grows, the inter-aggregate distance decreases, increasing network creation. The low strain modulus $E_{0}$ rises faster than the high strain modulus $E_{\infty}$ once the filler is added, resulting in a nonlinear viscoelastic behavior known as the Payne-effect $\left(E_{0}-E_{\infty}\right)$. The Payne effect is responsible for the decrease in modulus upto $10 \%$ strain. Enhanced high strain modulus
$(>30 \%)$ for both composites indicates a better in-rubber structure. The actual filler structure in the in-rubber state and the filler's surface activity are the two criteria that make up the in-rubber structure. The inrubber structure is a direct measure for the occluded rubber, which is protected from matrix deformation, resulting in a larger effective volume. Since no chemical bonds may develop between rubber and silica, surface activity can be attributed to physical bonds between the two. In both NRSF and NRSH composites, silica loading improves high strain modulus, indicating better polymer-filler interaction and thus reinforcement [31].

\subsection{Crosslink density and solvent swelling behaviour}

The swelling index and crosslink density of the NRSF and NRSH composites is given in Table 5. In both cases, the swelling index tends to decrease with increasing nano-silica loading. Silica addition improves

Table 5. Crosslink density and Swelling index of NR and NR/nano-silica composites.

\begin{tabular}{|c|c|c|}
\hline Sample name & $\begin{array}{c}\text { Crosslink density } \\
{\left[\mathbf{1 0}^{-\mathbf{5}} \mathbf{~} \mathbf{m o l} / \mathbf{g}\right]}\end{array}$ & $\begin{array}{c}\text { Swelling index } \\
{[\mathbf{\%}]}\end{array}$ \\
\hline NRSF0 & 3.7 & 522 \\
\hline NRSF1 & 4.0 & 480 \\
\hline NRSF2 & 5.0 & 424 \\
\hline NRSF3 & 5.6 & 391 \\
\hline NRSF4 & 6.0 & 372 \\
\hline NRSF5 & 6.1 & 364 \\
\hline NRSH0 & 5.0 & 407 \\
\hline NRSH1 & 5.4 & 386 \\
\hline NRSH3 & 5.7 & 369 \\
\hline NRSH5 & 6.7 & 326 \\
\hline NRSH7 & 4.7 & 396 \\
\hline
\end{tabular}


rubber-filler interaction, and hence swelling index shows a decreasing trend indicating a reduction in the solvent uptake. Rubber chains are immobilized on the rigid nano-silica network in NRSF and flexibility of the rubber chains are more retarded at higher concentration thereby hindering the solvent penetration. In the case of NRSH composites, this can be either due to the dilution effect or improved crosslink density, or both. An increase in silica-rubber interaction due to the homogenous distribution of nano-silica particles achieved by the latex stage mixing can also impart improved solvent resistance in the case of NRSH composites. Crosslink density improvement with silica loading is clear from the data and explains the reinforcing nature and hence enhancement in mechanical properties of the nanocomposites.

Silica particles inside the NR can create a difficult path and can hinder the solvent penetration inside the rubber. An increase in solvent uptake beyond $5 \mathrm{phr}$ for NRSH7 can be due to the presence of aggregates of silica at a high concentration which creates free spaces through which the solvents can easily penetrate $[32,33]$.

Table 6. TGA data for NRSF and NRSH nanocomposites.

\begin{tabular}{|c|c|c|c|c|c|c|c|c|c|}
\hline Property & NRSF0 & NRSF1 & NRSF3 & NRSF5 & NRSHO & NRSH1 & NRSH3 & NRSH5 & NRSH7 \\
\hline $\begin{array}{lll}\text { Onset degradation temperature, } & T_{0} & {\left[{ }^{\circ} \mathrm{C}\right]}\end{array}$ & 335 & 336 & 337 & 339 & 331 & 336 & 333 & 331 & 329 \\
\hline End set degradation temperature $\quad\left[{ }^{\circ} \mathrm{C}\right]$ & 463 & 477 & 478 & 481 & 483 & 476 & 484 & 477 & 479 \\
\hline $\begin{array}{l}\text { Maximum degradation temperature, } \\
\qquad T_{\max }\left[{ }^{\circ} \mathrm{C}\right]\end{array}$ & 391 & 392 & 393 & 392 & 390 & 390 & 391 & 391 & 391 \\
\hline Temperature at $50 \%$ degradation, $T_{50}\left[{ }^{\circ} \mathrm{C}\right]$ & 391 & 393 & 395 & 395 & 395 & 397 & 397 & 398 & 399 \\
\hline Residue at $600^{\circ} \mathrm{C}$ & 1.46 & 2.14 & 5.22 & 6.87 & 4.98 & 5.70 & 7.56 & 9.00 & 11.18 \\
\hline
\end{tabular}
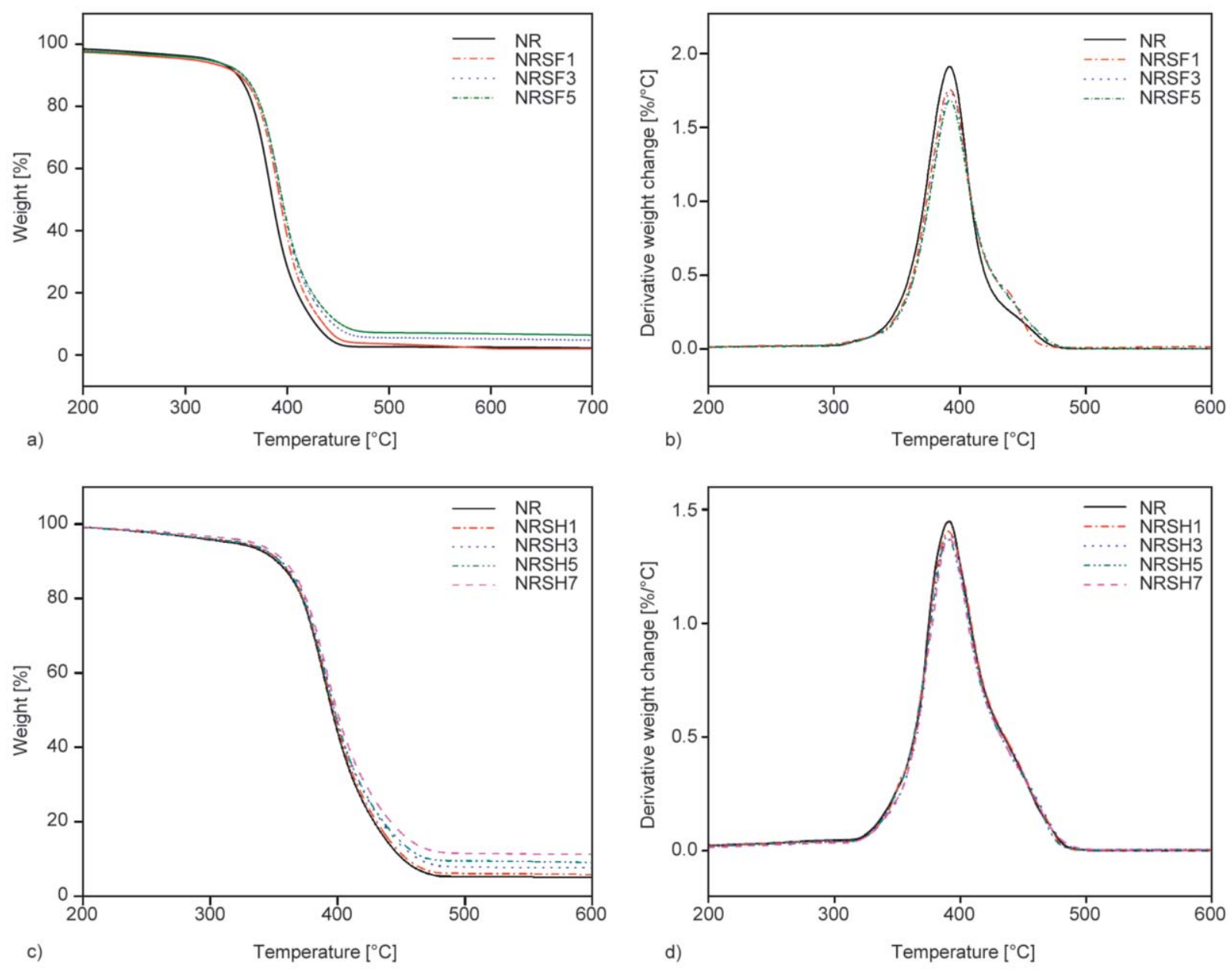

Figure 13. TGA and DTG curves of NRSF ( $a$ and $b$ ) and NRSH (c and d) nanocomposites. 


\subsection{Thermogravimetric analysis}

The influence of nano-silica on the thermal stability of NR in the present study is clear from the TGA results. Figure 13 shows the TGA and DTG curves, and Table 6 shows the relevant data. The results reveal that the thermal stability has not been affected by the presence of colloidal nano-silica, and there is only a nominal increase in the case of the onset, maximum degradation, and 50\% degradation temperature with silica loading in both composites compared to NR.

\section{Conclusions}

The study reveals that the processing method plays an important role in designing the distribution of filler inside the polymer matrix. NRSF composites fabricated by latex stage mixing followed by film casting method exhibited a network of nano-silica around the rubber spheres giving a beautiful segregated structure. NRSH composites prepared by latex stage incorporation of nano-silica followed by coagulation, drying, and mixing in Haake internal mixer, on the other hand, resulted in a random distribution of nano-silica inside NR. The difference in the filler morphology has been confirmed by TEM, SEM, and strain sweep studies. Improved solvent resistance and crosslink density observed for both nanocomposites indicate good rubber-filler interaction. Regardless of the processing conditions, the mechanical properties of both nanocomposites are enhanced with silica loading. NRSF 4 exhibited a $60 \%$ increase in tensile strength. NRSF5 showed a significant increase in tear strength by $157 \%$ and tensile modulus by $90 \%$. Tensile strength increased by $38 \%$, modulus by $28 \%$, and tear strength by $29 \%$ for NRSH5. Tremendous improvement in tear strength for the NRSF nanocomposites compared to NRSH is attributed to the rigid network of nano-silica around the rubber spheres, which can resist the propagation of the crack. These results suggest that the processing method influences the filler morphology inside a polymer which in turn affects the properties of the composite. Higher mechanical properties are obtained at 5 phr nano-silica loading in both NRSF and NRSH composites.

\section{Acknowledgements}

We gratefully acknowledge the University Grants Commission, India, for financial support, SAIF-STIC CUSAT for characterization facilities provided.

\section{References}

[1] Shah R.: Green tyres - Eco-friendly, safe and efficient. Auto Tech Review, 1, 52-55 (2012).

https://doi.org/10.1365/s40112-012-0125-6

[2] Heinrich G., Klüppel M., Vilgis T. A.: Reinforcement of elastomers. Current Opinion in Solid State and Materials Scienece, 6, 195-203 (2002). https://doi.org/10.1016/S1359-0286(02)00030-X

[3] Sahakaro K., Beraheng S.: Reinforcement of maleated natural rubber by precipitated silica. Journal of Applied Polymer Science, 109, 3839-3848 (2008).

https://doi.org/10.1002/app.28483

[4] Borapak W., Chueangchayaphan N., Pichaiyut S., Chueangchayaphan W.: Cure characteristics and physico-mechanical properties of natural rubber/silica composites: Effect of natural rubber-graft-poly(2-hydroxyethyl acrylate) content. Polymer Bulletin, 78, 20092023 (2021).

https://doi.org/10.1007/s00289-020-03199-z

[5] Kohjiya S., Ikeda Y.: In situ formation of particulate silica in natural rubber matrix by the sol-gel reaction. Journal of Sol-Gel Science and Technology, 26, 495-498 (2003).

https://doi.org/10.1023/A:1020743214628

[6] Poompradub S., Thirakulrati M., Prasassarakich P.: In situ generated silica in natural rubber latex via the solgel technique and properties of the silica rubber composites. Materials Chemistry and Physics, 144, 122131 (2014).

https://doi.org/10.1016/j.matchemphys.2013.12.030

[7] Lin Y., Zhang A., Sun J., Wang L.: Properties of natural rubber vulcanizates/nanosilica composites prepared based on the method of in-situ generation and coagulation. Journal of Macromolecular Science Part B: Physics, 52, 1494-1507 (2013).

https://doi.org/10.1080/00222348.2013.763562

[8] Prasertsri S., Rattanasom N.: Fumed and precipitated silica reinforced natural rubber composites prepared from latex system: Mechanical and dynamic properties. Polymer Testing, 31, 593-605 (2012).

https://doi.org/10.1016/j.polymertesting.2012.03.003

[9] Prasertsri S., Rattanasom N.: Mechanical and damping properties of silica/natural rubber composites prepared from latex system. Polymer Testing, 30, 515-526 (2011). https://doi.org/10.1016/j.polymertesting.2011.04.001

[10] Tai X., Ma J. H., Du Z., Wang W., Wu J.: A simple method for synthesis of thermal responsive silica nanoparticle/PNIPAAm hybrids. Powder Technology, 233, 47-51 (2013).

https://doi.org/10.1016/j.powtec.2012.08.026

[11] Pérez-Quintanilla D., del Hierro I., Fajardo M., Sierra I.: Adsorption of cadmium(II) from aqueous media onto a mesoporous silica chemically modified with 2-mercaptopyrimidine. Journal of Materials Chemistry, 16, 17571764 (2006). https://doi.org/10.1039/B518157G 
[12] Wei L., Hu N., Zhang Y.: Synthesis of polymer-mesoporous silica nanocomposites. Materials, 3, 4066-4079 (2010). https://doi.org/10.3390/ma3074066

[13] Singh D., Kumar R., Kumar A., Rai K. N.: Synthesis and characterization of rice husk silica, silica-carbon composite and $\mathrm{H}_{3} \mathrm{PO}_{4}$ activated silica. Ceramica, 54, 203 212 (2008). https://doi.org/10.1590/S0366-69132008000200011

[14] George N., Bipinbal P. K., Bhadran B., Mathiazhagan A., Joseph R.: Segregated network formation of multiwalled carbon nanotubes in natural rubber through surfactant assisted latex compounding: A novel technique for multifunctional properties. Polymer, 112, 264-277 (2017). https://doi.org/10.1016/j.polymer.2017.01.082

[15] George N., Chandra J. C. S., Mathiazhagan A., Joseph R.: High performance natural rubber composites with conductive segregated network of multiwalled carbon nanotubes. Composites Science and Technology, 116, 33-40 (2015).

https://doi.org/10.1016/j.compscitech.2015.05.008

[16] George N., Venugopal B., John H., Mathiazhagan A., Joseph R.: Nanosilica decorated multiwalled carbon nanotubes (CS hybrids) in natural rubber latex. Polymer, 161, 170-180 (2019).

https://doi.org/10.1016/j.polymer.2018.12.014

[17] Sarkawi S. S.: Nano-reinforcement of tire rubbers: Silica-technology for natural rubber: Exploring the infuence of non-rubber constituents on the natural rubber-silica system. PhD Thesis, University of Twente (2013). https://doi.org/10.3990/1.9789036500715

[18] Mostafa A., Abouel-Kasem A., Bayoumi M. R., El-Sebaie M. G.: Rubber-filler interactions and its effect in rheological and mechanical properties of filled compounds. Journal of Testing and Evaluation, 38, 347 359 (2010). https://doi.org/10.1520/JTE101942

[19] Blow C. M.: Rubber technology and manufacture. Butterworths, London (1971).

[20] Steward P. A., Hearn J., Wilkinson M. C.: An overview of polymer latex film formation and properties. Advances in Colloid and Interface Science, 86, 195-267 (2000).

https://doi.org/10.1016/S0001-8686(99)00037-8

[21] Potts J. R., Shankar O., Du L., Ruoff R. S.: Processingmorphology-property relationships and composite theory analysis of reduced graphene oxide/natural rubber nanocomposites. Macromolecules, 45, 6045-6055 (2012). https://doi.org/10.1021/ma300706k

[22] Potts J. R., Shankar O., Murali S., Du L., Ruoff R. S.: Latex and two-roll mill processing of thermally-exfoliated graphite oxide/natural rubber nanocomposites. Composites Science and Technology, 74, 166-172 (2013).

https://doi.org/10.1016/j.compscitech.2012.11.008
[23] Pang H., Yan D-X., Bao Y., Chen J-B., Chen C., Li Z-M.: Super-tough conducting carbon nanotube/ultrahighmolecular-weight polyethylene composites with segregated and double-percolated structure. Journal of Materials Chemistry, 22, 23568-23575 (2012).

https://doi.org/10.1039/C2JM34793H

[24] Zare Y.: Study of nanoparticles aggregation/agglomeration in polymer particulate nanocomposites by mechanical properties. Composites Part A: Applied Science and Manufacturing, 84, 158-164 (2016). https://doi.org/10.1016/j.compositesa.2016.01.020

[25] Zhan Y., Lavorgna M., Buonocore G., Xia H.: Enhancing electrical conductivity of rubber composites by constructing interconnected network of self-assembled graphene with latex mixing. Journal of Materials Chemistry, 22, 10464-10468 (2012).

https://doi.org/10.1039/C2JM31293J

[26] Jin S. H., Park Y-B, Yoon K. H.: Rheological and mechanical properties of surface modified multi-walled carbon nanotube-filled PET composite. Composites Science and Technology, 67, 3434-3441 (2007).

https://doi.org/10.1016/j.compscitech.2007.03.013

[27] Bachmann J. H., Sellers J. W., Wagner M. P., Wolf R. F.: Fine particle reinforcing silicas and silicates in elastomers. Rubber Chemistry and Technology, 32, 12861391 (1959).

https://doi.org/10.5254/1.3542491

[28] Payne A. R., Whittaker R. E., Smith J. F.: Effect of vulcanization on the low-strain dynamic properties of filled rubbers. Journal of Applied Polymer Science, 16, 11911212 (1972). https://doi.org/10.1002/app.1972.070160513

[29] Meera A. P., Said S., Grohens Y., Thomas S.: Nonlinear viscoelastic behavior of silica-filled natural rubber nanocomposites. Journal of Physical Chemistry C, 113, 17997-18002 (2009). https://doi.org/10.1021/jp9020118

[30] Medalia A. I.: Effect of carbon black on dynamic properties of rubber vulcanizates. Rubber Chemistry and Technology, 51, 437-523 (1978). https://doi.org/10.5254/1.3535748

[31] Fröhlich J., Niedermeier W., Luginsland H-D.: The effect of filler-filler and filler-elastomer interaction on rubber reinforcement. Composites Part A: Applied Science and Manufacturing, 36, 449-460 (2005). https://doi.org/10.1016/j.compositesa.2004.10.004

[32] Galimberti M., Cipolletti V., Musto S., Cioppa S., Peli G., Mauro M., Gaetano G., Agnelli S., Theonis R., Kumar V.: Recent advancements in rubber nanocomposites. Rubber Chemistry and Technology, 87, 417-442 (2014). https://doi.org/10.5254/rct.14.86919

[33] Abraham J., Maria H. J., George S. C., Kalarikkal N., Thomas S.: Transport characteristics of organic solvents through carbon nanotube filled styrene butadiene rubber nanocomposites: The influence of rubber-filler interaction, the degree of reinforcement and morphology. Physical Chemistry Chemical Physics, 17, 1121711228 (2015).

https://doi.org/10.1039/C5CP00719D 